\title{
Microstructure in precursor formed by controlling composition of condensed boric acid-poly(vinyl alcohol) product for low-temperature synthesis of boron carbide powder
}

\author{
Masaki KAKIAGE, ${ }^{\dagger}$ Naoki TAHARA, Rie WATANABE, Ikuo YANASE and Hidehiko KOBAYASHI \\ Department of Applied Chemistry, Graduate School of Science and Engineering, Saitama University, \\ 255 Shimo-Okubo, Sakura-ku, Saitama 338-8570, Japan
}

\begin{abstract}
The dispersion state of boron oxide $\left(\mathrm{B}_{2} \mathrm{O}_{3}\right)$ and carbon components in a precursor prepared from a condensed boric acid $\left(\mathrm{H}_{3} \mathrm{BO}_{3}\right)$-polyol product by thermal decomposition in air was found to be closely related to the formation of boron carbide $\left(\mathrm{B}_{4} \mathrm{C}\right)$ powder at a low synthesis temperature. The microstructure in the precursor was fabricated by controlling the composition of a condensed $\mathrm{H}_{3} \mathrm{BO}_{3}$-poly(vinyl alcohol) (PVA) product. The size of $\mathrm{B}_{2} \mathrm{O}_{3}$ particles dispersed in the carbon matrix of the microstructure decreased with increasing PVA content of the condensed product. Crystalline $\mathrm{B}_{4} \mathrm{C}$ powder with a little free carbon was synthesized from a precursor with a more finely and homogeneously dispersed structure consisting of $\mathrm{B}_{2} \mathrm{O}_{3}$ particles and the carbon matrix by heat treatment at $1200^{\circ} \mathrm{C}$ for $5 \mathrm{~h}$ in an $\mathrm{Ar}$ flow. Furthermore, the formation and subsequent grain growth of $B_{4} C$ particles were promoted even at a low synthesis temperature.
\end{abstract}

(C)2013 The Ceramic Society of Japan. All rights reserved.

Key-words : Boron carbide $\left(\mathrm{B}_{4} \mathrm{C}\right)$, Precursor, Microstructure, Poly(vinyl alcohol), Low-temperature synthesis

[Received August 1, 2012; Accepted October 9, 2012]

\section{Introduction}

The low-temperature synthesis method of boron carbide $\left(\mathrm{B}_{4} \mathrm{C}\right)$ powder, which is an important non-oxide ceramic with attractive properties and superior functions, has recently been investigated. The carbothermal reduction of boron oxide $\left(\mathrm{B}_{2} \mathrm{O}_{3}\right)$, for which the overall reaction is given by Eq. (1), is used to produce $\mathrm{B}_{4} \mathrm{C}$ owing to the use of inexpensive and nonhazardous raw materials, but the process is performed at a high temperature of approximately $2000^{\circ} \mathrm{C}$. . $^{1), 2)}$

$$
2 \mathrm{~B}_{2} \mathrm{O}_{3}+7 \mathrm{C} \rightarrow \mathrm{B}_{4} \mathrm{C}+6 \mathrm{CO}
$$

Carbothermal reduction using a condensed product that is made up of boric acid $\left(\mathrm{H}_{3} \mathrm{BO}_{3}\right)$ and a polyol is attractive as a low-temperature synthesis method of $\mathrm{B}_{4} \mathrm{C}$ powder. ${ }^{2)-8)}$ The condensed product forms a borate ester $(\mathrm{B}-\mathrm{O}-\mathrm{C})$ bond by a dehydration condensation reaction between $\mathrm{H}_{3} \mathrm{BO}_{3}$ and the polyol. This reaction accelerates the dispersion of boron and carbon sources, and thus the synthesis temperature is reduced. However, the obtained product contains a large amount of residual carbon, which is a common disadvantage of $\mathrm{B}_{4} \mathrm{C}$ synthesis using a polyol. We performed the thermal decomposition of a condensed $\mathrm{H}_{3} \mathrm{BO}_{3}$-polyol product in air to control the amount of carbon to the stoichiometric ratio required for the carbothermal reduction [Eq. (1)], ${ }^{9)-13)}$ whereby crystalline $\mathrm{B}_{4} \mathrm{C}$ powder with little free carbon was synthesized by heat treatment at $1250^{\circ} \mathrm{C}$ for $5 \mathrm{~h}$ in an Ar flow. ${ }^{10-13)}$ The obtained thermally decomposed product consisted of highly dispersed $\mathrm{B}_{2} \mathrm{O}_{3}$ and carbon components. ${ }^{10), 11), 13)}$ Note that the synthesis temperature is expected to be lowered by improving the dispersion of the $\mathrm{B}_{2} \mathrm{O}_{3}$ and carbon components owing to the increased interface between the $\mathrm{B}_{2} \mathrm{O}_{3}$ and carbon components with superior reactivity. ${ }^{10)-12)}$

Corresponding author: M. Kakiage; E-mail: kakiage@apc. saitama-u.ac.jp
Poly(vinyl alcohol) (PVA) is a typical polyol as well as a water-soluble polymer and readily forms a $\mathrm{B}-\mathrm{O}-\mathrm{C}$ bond with $\mathrm{H}_{3} \mathrm{BO}_{3}$ by dehydration condensation. Thus, PVA is useful as a carbon source for the low-temperature synthesis of $\mathrm{B}_{4} \mathrm{C}$ powder. The morphology of the precursor obtained by the thermal decomposition of the condensed $\mathrm{H}_{3} \mathrm{BO}_{3}$-PVA product in air exhibits the dispersion of $\mathrm{B}_{2} \mathrm{O}_{3}$ particles in a carbon matrix, ${ }^{11)}$ which is similar to the sea-island structure of a polymer alloy. This indicates that the morphological characteristics of a matrix polymer strongly determine the morphology of the precursor.

Our previous study revealed that a precursor with a homogeneously arranged $\mathrm{B}_{2} \mathrm{O}_{3}$ /carbon structure at the nanometer scale prepared from a condensed $\mathrm{H}_{3} \mathrm{BO}-\mathrm{PVA}$ product enables the use of a lower synthesis temperature and a shorter holding time. ${ }^{11)}$ It is known that the phase-separated morphology of a polymer alloy is related to the volume fraction of each component. Furthermore, the number of hydroxyl groups of PVA, which react with $\mathrm{H}_{3} \mathrm{BO}_{3}$, in a condensed product increases with increasing PVA content, increasing the dispersion of $\mathrm{H}_{3} \mathrm{BO}_{3}$.

In this study, the desired microstructure of the $\mathrm{B}_{2} \mathrm{O}_{3} /$ carbon precursor is formed by controlling the composition of the condensed $\mathrm{H}_{3} \mathrm{BO}_{3}-\mathrm{PVA}$ product to achieve the low-temperature synthesis of $\mathrm{B}_{4} \mathrm{C}$ powder. We considered the effect of the PVA content of a condensed product on the microstructure in the precursor consisting of $\mathrm{B}_{2} \mathrm{O}_{3}$ particles and the carbon matrix. The formation of $\mathrm{B}_{4} \mathrm{C}$ at a low synthesis temperature and its morphology were investigated.

\section{Experimental procedure}

\subsection{Synthesis of $\mathrm{B}_{4} \mathrm{C}$ powder}

PVA was supplied by Kuraray Co., Ltd., Japan, for which the degrees of polymerization and hydrolysis were 320 and $98.5 \mathrm{~mol} \%$, respectively. $\mathrm{H}_{3} \mathrm{BO}_{3}(99.5 \%)$ was purchased from Wako Pure Chemical Industries, Ltd., Japan. These materials were used as received. A condensed product was prepared by the 
dehydration condensation of $\mathrm{H}_{3} \mathrm{BO}_{3}$ and PVA with a $\mathrm{H}_{3} \mathrm{BO}_{3}$ :PVA (hydroxyl group of PVA) molar ratio of 1:3-6. PVA was dissolved in distilled water (ca. $5 \mathrm{wt} \%$ ) by stirring and heating in a water bath at $80^{\circ} \mathrm{C}$ for $1 \mathrm{~h}$. The concentration of the PVA solution was kept at a constant regardless of the molar ratio. Then, $\mathrm{H}_{3} \mathrm{BO}_{3}$ was dissolved in distilled water (ca. 1-2 wt \%) and added dropwise to the PVA solution. The blended solution was heated until the water evaporated, which was followed by drying at $120^{\circ} \mathrm{C}$ in air. The resulting product was a white solid.

Thermal decomposition in air was performed to eliminate the excess carbon component; the condensed product was placed in an alumina crucible after grinding with an agate mortar and pestle, and thermally decomposed in air. The thermal decomposition conditions (temperature and holding time) were determined with the aim of achieving the stoichiometric $\mathrm{C} / \mathrm{B}_{2} \mathrm{O}_{3}$ ratio $(=3.5)$ for the carbothermal reduction [Eq. (1)]. The black precursors obtained by the thermal decomposition of the condensed products in air were ground with an agate mortar and pestle into powder form. The precursor powders are denoted P3-P6 according to the molar ratio of PVA (listed in Table 1). Each precursor powder was placed in a graphite boat and heated at $1050-1250^{\circ} \mathrm{C}$ for $0-20 \mathrm{~h}$ in an Ar flow $(200 \mathrm{ml} / \mathrm{min})$ at a heating rate of $10^{\circ} \mathrm{C} / \mathrm{min}$.

\subsection{Characterization}

The $\mathrm{B}_{2} \mathrm{O}_{3}$ content of the precursor powder was determined as the $\mathrm{H}_{3} \mathrm{BO}_{3}$ content by titrating a mannitol- $\mathrm{H}_{3} \mathrm{BO}_{3}$ complex with sodium hydroxide solution using phenolphthalein as the indicator. The $\mathrm{B}_{2} \mathrm{O}_{3}$ component was removed from the precursor powder by washing in hot water. A Rigaku Thermo Plus TG8120 was used for the thermogravimetric (TG) measurements of PVA and the condensed products. Heating scans were performed up to

Table 1. Preparation conditions and $\mathrm{C} / \mathrm{B}_{2} \mathrm{O}_{3}$ ratio of each precursor

\begin{tabular}{cccc}
\hline $\begin{array}{c}\text { Precursor } \\
\text { code }\end{array}$ & $\begin{array}{c}\text { Molar ratio } \\
{\left[\mathrm{H}_{3} \mathrm{BO}_{3}: \mathrm{PVA}\right.} \\
(\mathrm{OH} \text { group })]\end{array}$ & $\begin{array}{c}\text { Thermal } \\
\text { decomposition } \\
\text { conditions }\end{array}$ & $\begin{array}{c}\mathrm{C} / \mathrm{B}_{2} \mathrm{O}_{3} \\
\text { ratio }\end{array}$ \\
\hline P3 & $1: 3$ & $500^{\circ} \mathrm{C}-2 \mathrm{~h}$ & 3.4 \\
P4 & $1: 4$ & $600^{\circ} \mathrm{C}-2 \mathrm{~h}$ & 3.4 \\
P5 & $1: 5$ & $650^{\circ} \mathrm{C}-1.5 \mathrm{~h}$ & 3.2 \\
P6 & $1: 6$ & $700^{\circ} \mathrm{C}-1 \mathrm{~h}$ & 3.3 \\
\hline
\end{tabular}
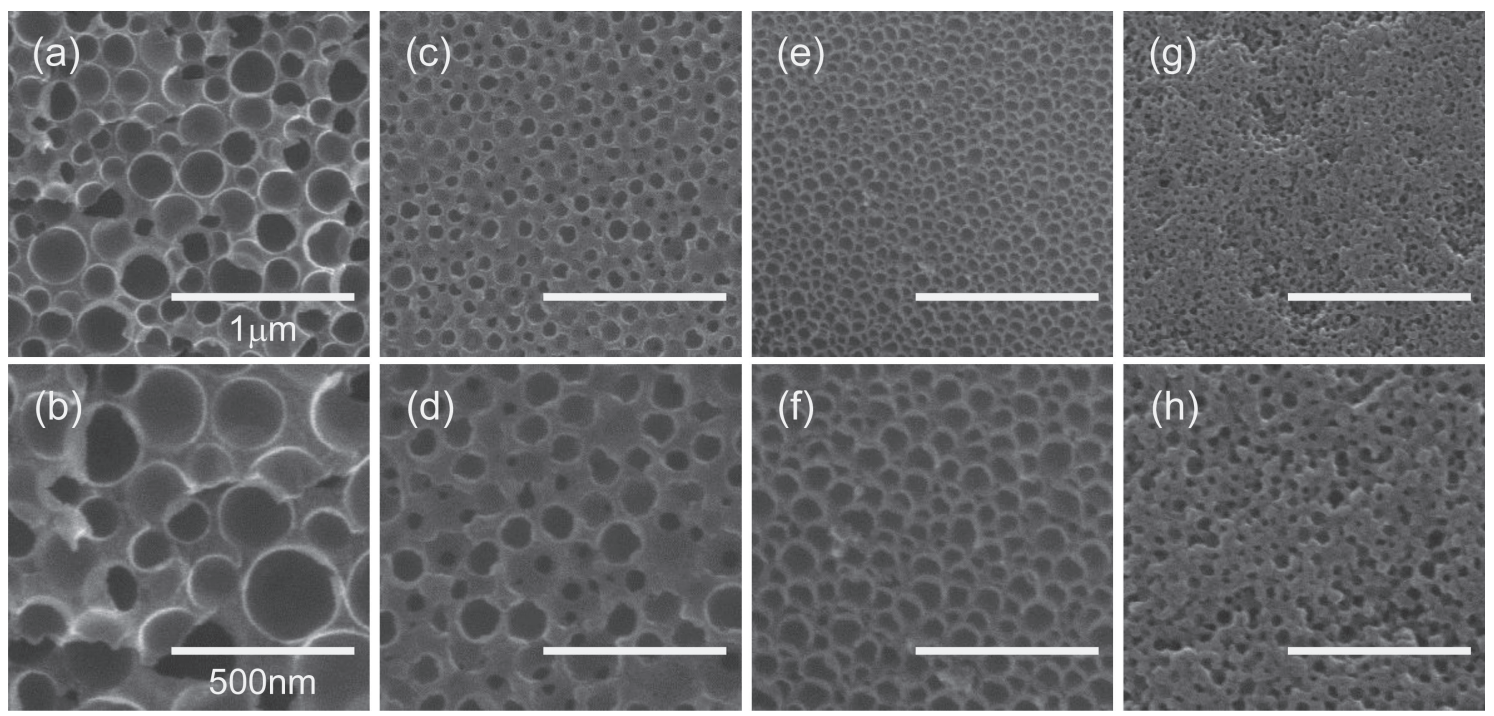

$700^{\circ} \mathrm{C}$ at a rate of $10^{\circ} \mathrm{C} / \mathrm{min}$ in air. Scanning electron microscopy (SEM) observations of the morphologies of the precursor and product powders were conducted with a Hitachi S-4100 fieldemission scanning electron microscope operated at $15.0 \mathrm{kV}$. The samples were coated with 5-nm-thick Pt-Pd before the observation. X-ray diffraction (XRD) measurements of the products were performed using a powder X-ray diffractometer (Rigaku RINT2200) operated at $40 \mathrm{kV}$ and $30 \mathrm{~mA}$ with monochromatized $\mathrm{Cu} \mathrm{K} \alpha$ radiation. The $\mathrm{B}_{4} \mathrm{C}$ peak intensity ratio $\left[I_{\mathrm{B}_{4} \mathrm{C}} /\left(I_{\mathrm{B}_{4} \mathrm{C}}+\right.\right.$ $\left.\left.I_{\mathrm{C}}+I_{\mathrm{B}_{2} \mathrm{O}_{3}}\right)\right]$ of the products was estimated from the main peak intensities of the $\mathrm{B}_{4} \mathrm{C}\left[I_{\mathrm{B}_{4} \mathrm{C}} ;(021)\right.$ reflection at $\left.2 \theta=37.8^{\circ}\right]$, carbon $\left(I_{\mathrm{C}}\right.$; amorphous halo at $\left.2 \theta=23-27^{\circ}\right)$, and $\mathrm{B}_{2} \mathrm{O}_{3}\left[I_{\mathrm{B}_{2} \mathrm{O}_{3}}\right.$; (031) reflection at $\left.2 \theta=27.8^{\circ}\right]$ components in the XRD pattern. $\mathrm{CHN}$ elemental analyses were performed by a combustion method with a gas chromatograph using a FlashEA 1112 elemental analyzer (Thermo Electron Corporation). The residual free carbon content was estimated from an amount of carbon in the product after the washing in hot water.

\section{Results and discussion}

The thermal behavior of the condensed products was investigated to characterize the state of each condensed product. Figure 1 shows the TG curves of PVA and the condensed products. Similar decomposition behavior was observed for all

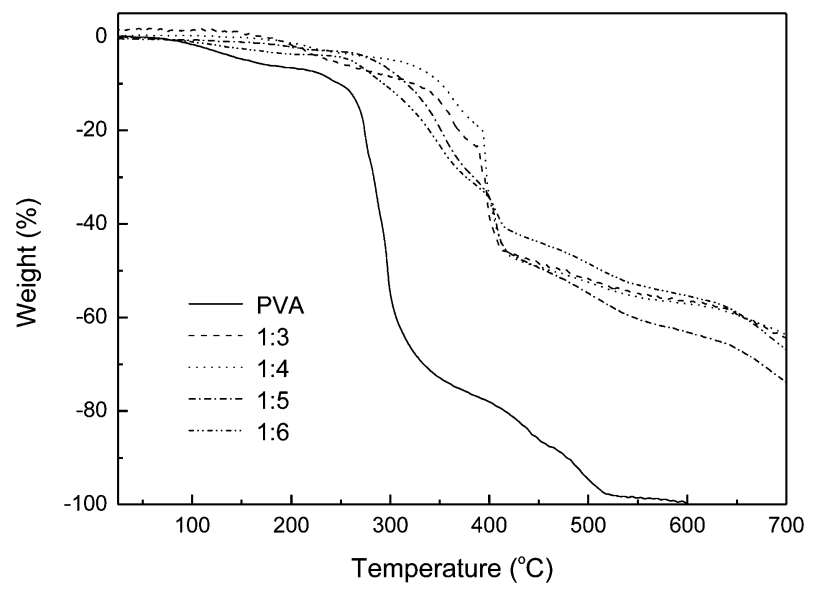

Fig. 1. TG curves of PVA and condensed products.

Fig. 2. SEM images of $(\mathrm{a}, \mathrm{b}) \mathrm{P} 3$, (c, d) $\mathrm{P} 4$, (e, f) $\mathrm{P} 5$, and $(\mathrm{g}, \mathrm{h}) \mathrm{P} 6$ after removal of $\mathrm{B}_{2} \mathrm{O}_{3}$ by washing in hot water 
condensed products, which was completely different from that of PVA. Significant decomposition of the condensed products took place at $400^{\circ} \mathrm{C}$, which is higher than that for PVA $\left(300^{\circ} \mathrm{C}\right)$. This indicates the formation of $\mathrm{B}-\mathrm{O}-\mathrm{C}$ bonds by dehydration condensation. Furthermore, the decomposition corresponding to PVA was not observed for the condensed product with the highest PVA content $\left(\mathrm{H}_{3} \mathrm{BO}_{3}: \mathrm{PVA}=1: 6\right)$, and the weight loss attributed to the dehydration of $\mathrm{H}_{3} \mathrm{BO}_{3}$ below $200^{\circ} \mathrm{C}$ was not observed for the condensed product with the highest $\mathrm{H}_{3} \mathrm{BO}_{3}$ content $\left(\mathrm{H}_{3} \mathrm{BO}_{3}: \mathrm{PVA}=1: 3\right)$. These demonstrate the nonexistence of unreacted starting materials without $\mathrm{B}-\mathrm{O}-\mathrm{C}$ bonds in the condensed product prepared in this study.

The dispersion state of the $\mathrm{B}_{2} \mathrm{O}_{3}$ and carbon components in the precursors was investigated by SEM observation. A series of SEM images of the precursors after washing in hot water is shown in Fig. 2. The $\mathrm{B}_{2} \mathrm{O}_{3}$ component can be removed by washing the precursor powder in hot water, thus leaving the carbon component. Nanosize $\mathrm{B}_{2} \mathrm{O}_{3}$ particles were dispersed in a carbon matrix for all precursors, and the dispersibility markedly improved with increasing PVA content of the condensed product. Among the precursors, P3 had an extremely disordered structure with larger $\mathrm{B}_{2} \mathrm{O}_{3}$ particles. The pore size distributions of the precursors estimated from their SEM images are shown in Fig. 3. The pore size and its variation decreased with increasing PVA content of the condensed product. The pore size for P6, which has the smallest pores, was $50 \mathrm{~nm}$ or less. Therefore, the significantly improved dispersibility of $\mathrm{B}_{2} \mathrm{O}_{3}$ particles in the carbon matrix of the precursor can be clearly attributed to the PVA content of the condensed product. A network of PVA chains
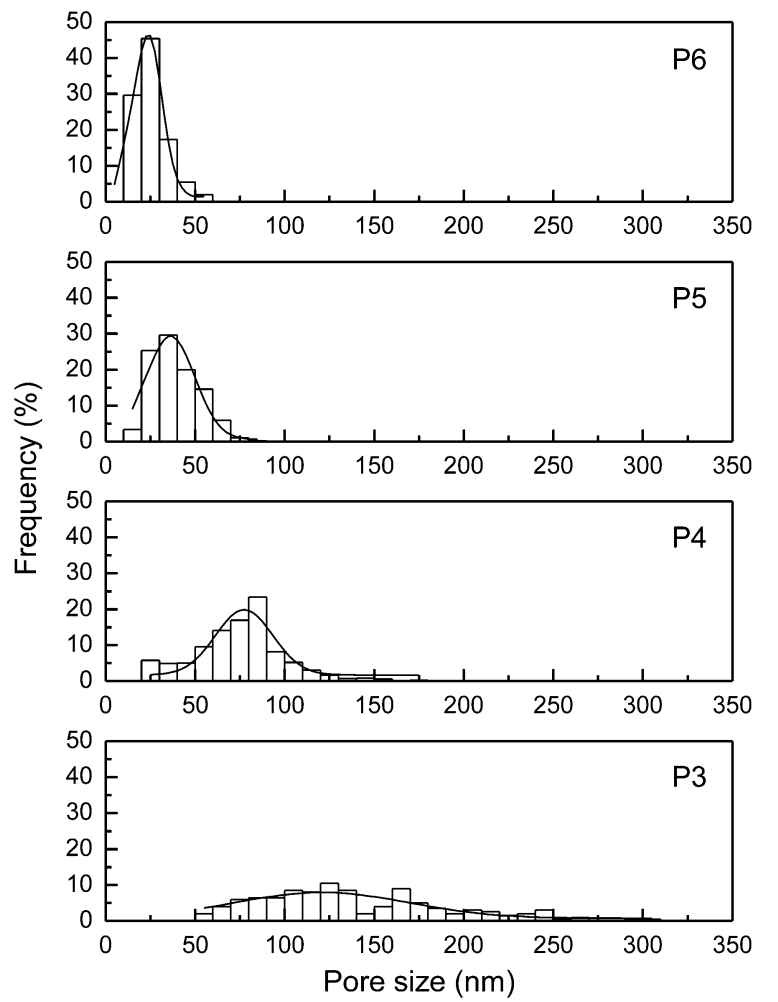

Fig. 3. Pore size distributions of precursors estimated from SEM images.
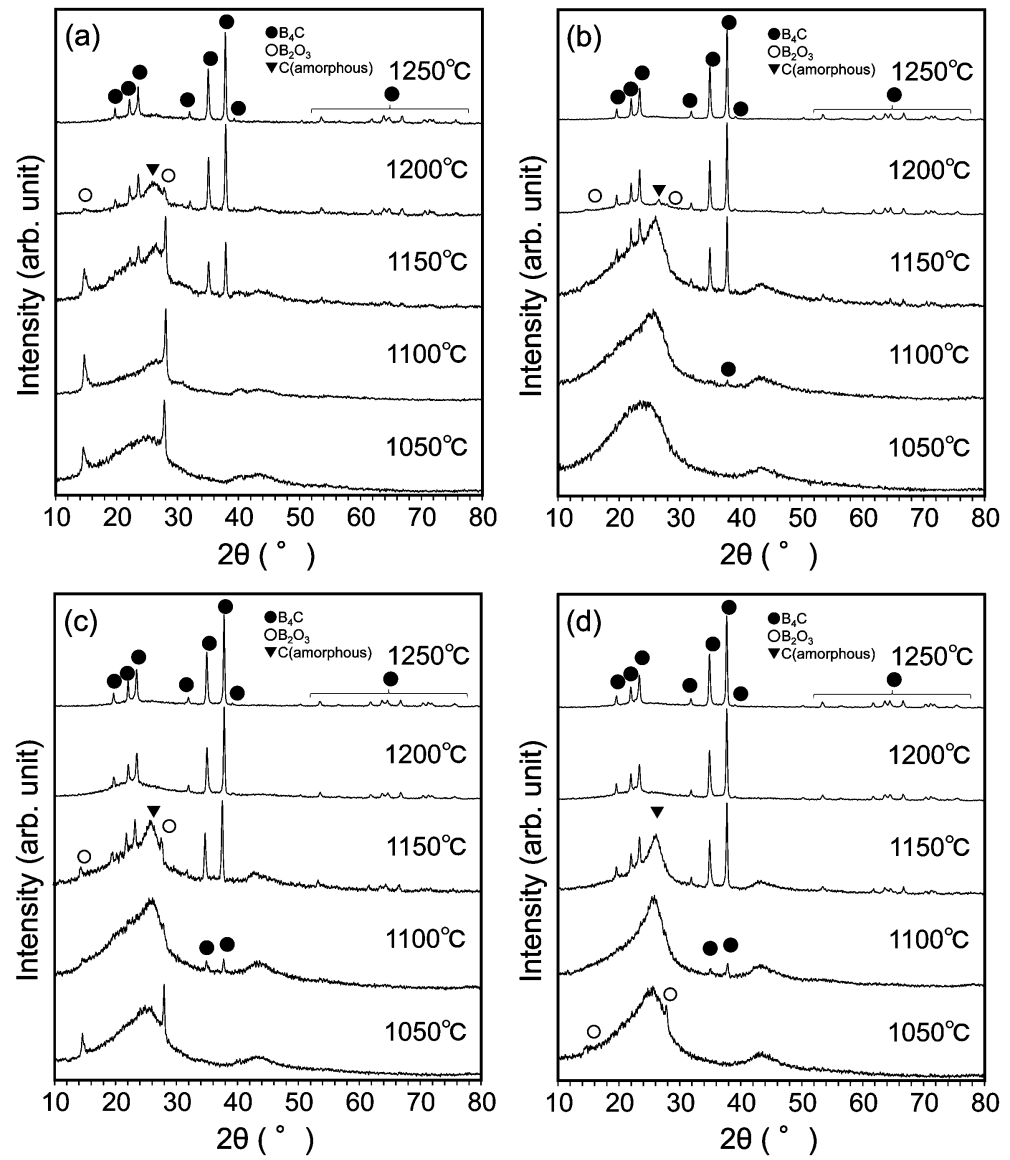

Fig. 4. XRD patterns of products obtained by heat treatment of (a) P3, (b) P4, (c) P5, and (d) $\mathrm{P} 6$ at $1050-1250^{\circ} \mathrm{C}$ for $5 \mathrm{~h}$ in an Ar flow. 


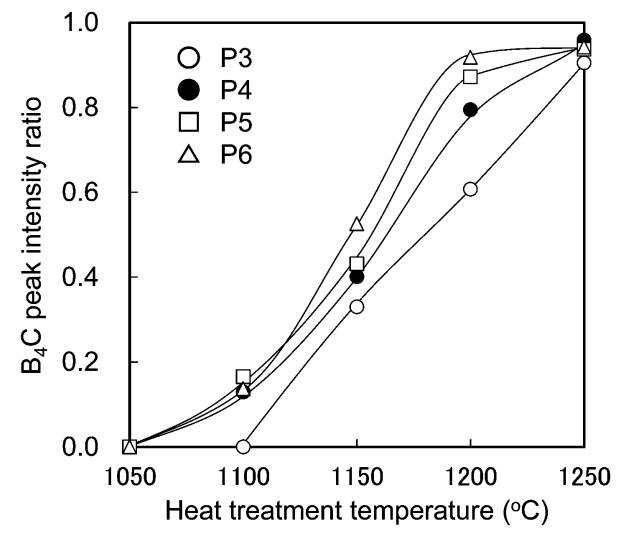

Fig. 5. Changes in $\mathrm{B}_{4} \mathrm{C}$ peak intensity ratio for products prepared from P3-P6 by heat treatment at $1050-1250^{\circ} \mathrm{C}$ for $5 \mathrm{~h}$ in an Ar flow.

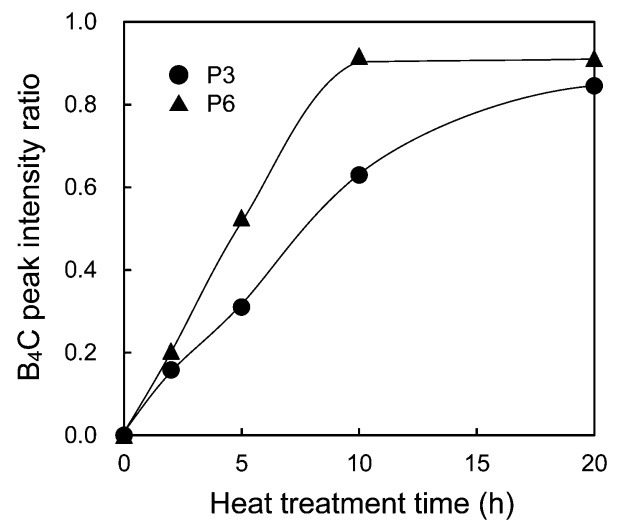

Fig. 7. Changes in $\mathrm{B}_{4} \mathrm{C}$ peak intensity ratio for products prepared from $\mathrm{P} 3$ and $\mathrm{P} 6$ by heat treatment at $1150^{\circ} \mathrm{C}$ for $0-20 \mathrm{~h}$ in an Ar flow.
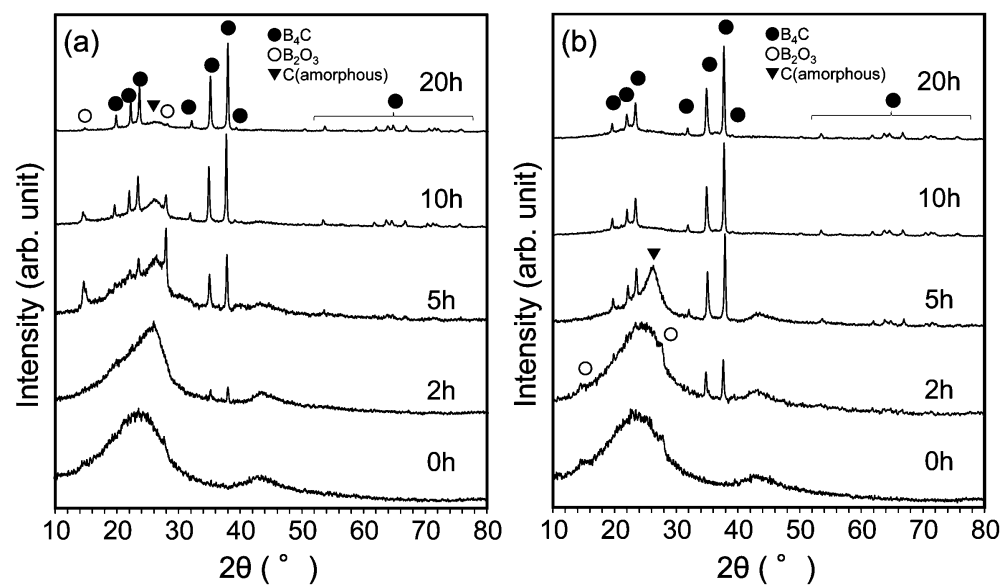

Fig. 6. XRD patterns of products obtained by heat treatment of (a) P3 and (b) P6 at $1150^{\circ} \mathrm{C}$ for $0-20 \mathrm{~h}$ in an $\mathrm{Ar}$ flow.

with hydroxyl groups is structured in the PVA solution. Voids with hydroxyl groups between PVA chains, i.e., the diffusion field of $\mathrm{H}_{3} \mathrm{BO}_{3}$ molecules, increase with increasing PVA content. Thus, in the preparation of the condensed product, $\mathrm{H}_{3} \mathrm{BO}_{3}$ molecules can be more finely dispersed into the network of PVA for the condensed product with higher PVA content. Consequently, the aggregation of $\mathrm{B}_{2} \mathrm{O}_{3}$ was suppressed and a precursor having a finely and homogeneously dispersed structure is fabricated.

The XRD patterns of the products obtained by the heat treatment of each precursor at $1050-1250^{\circ} \mathrm{C}$ for $5 \mathrm{~h}$ in an Ar flow are shown in Fig. 4. Peaks corresponding to a rhombohedral $\mathrm{B}_{4} \mathrm{C}$ crystal were observed at $1150^{\circ} \mathrm{C}$ for $\mathrm{P} 3$ and at $1100^{\circ} \mathrm{C}$ for $\mathrm{P} 4, \mathrm{P} 5$, and $\mathrm{P} 6$. The starting temperature of $\mathrm{B}_{4} \mathrm{C}$ formation is closely related to the dispersion of $\mathrm{B}_{2} \mathrm{O}_{3}$ particles in the precursor. ${ }^{11)}$ Only $\mathrm{B}_{4} \mathrm{C}$ peaks appeared at $1250^{\circ} \mathrm{C}$ for $\mathrm{P} 3$ and $\mathrm{P} 4$ and at $1200^{\circ} \mathrm{C}$ for $\mathrm{P} 5$ and $\mathrm{P} 6$. Changes in the $\mathrm{B}_{4} \mathrm{C}$ peak intensity ratio of the products prepared from $\mathrm{P} 3-\mathrm{P} 6$ with the heat treatment temperature in the case of heat treatment for $5 \mathrm{~h}$ in an Ar flow are summarized in Fig. 5. The peak intensity ratio increased from P3, which has the poorly dispersed structure, to P6, which has the most finely dispersed structure, at the same heat treatment temperature. This demonstrates that the dispersion of the $\mathrm{B}_{2} \mathrm{O}_{3}$ and carbon components is a dominant factor in the formation of $\mathrm{B}_{4} \mathrm{C}$. A finely dispersed structure leads to a larger interface between the $\mathrm{B}_{2} \mathrm{O}_{3}$ and carbon components with superior reactivity, enabling the low-temperature synthesis of $\mathrm{B}_{4} \mathrm{C}$. From
$\mathrm{P} 5$ and $\mathrm{P} 6$, crystalline $\mathrm{B}_{4} \mathrm{C}$ powder with a little free carbon was synthesized at $1200^{\circ} \mathrm{C}$, which is the lowest temperature reported for the synthesis of $\mathrm{B}_{4} \mathrm{C}$ powder at a holding time of $5 \mathrm{~h}$ using a polyol. The residual free carbon content in the product obtained by the heat treatment of $\mathrm{P} 6$ at $1200^{\circ} \mathrm{C}$ for $5 \mathrm{~h}$ in an Ar flow after the washing in hot water was $4.6 \mathrm{wt} \%$.

The synthesis reaction of $\mathrm{B}_{4} \mathrm{C}$ mainly occurs at the interface between the $\mathrm{B}_{2} \mathrm{O}_{3}$ and carbon components at the low synthesis temperature in order to facilitate the diffusion of reacting species. Hence, a finely dispersed precursor with a large interface is expected to readily produce $\mathrm{B}_{4} \mathrm{C}$ at a low synthesis temperature. Figure 6 shows the XRD patterns of the products obtained from P3 (poor dispersion) and P6 (fine dispersion) by heat treatment at $1150^{\circ} \mathrm{C}$ for $0-20 \mathrm{~h}$ in an Ar flow. Changes in the $\mathrm{B}_{4} \mathrm{C}$ peak intensity ratio with the heat treatment time are summarized in Fig. 7. The formation of $\mathrm{B}_{4} \mathrm{C}$ from $\mathrm{P} 6$ was saturated at a heat treatment time of $10 \mathrm{~h}$. In contrast, for $\mathrm{P} 3$, the $\mathrm{B}_{4} \mathrm{C}$ peak intensity ratio increased slowly with increasing heat treatment time, and small amounts of unreacted $\mathrm{B}_{2} \mathrm{O}_{3}$ and carbon were observed even after heat treatment for $20 \mathrm{~h}$. The diffusion of reacting species readily occurs for the precursor with high dispersion and high homogeneity, and thus $\mathrm{B}_{4} \mathrm{C}$ powder was synthesized at a shorter time from P6. These results demonstrate that the $\mathrm{B}_{4} \mathrm{C}$ formation reaction occurs homogeneously in the precursor with a homogeneous dispersion and suggest that the synthesis temperature and holding time can be reduced by using a precursor with a finely and homogeneously dispersed structure consisting of $\mathrm{B}_{2} \mathrm{O}_{3}$ 

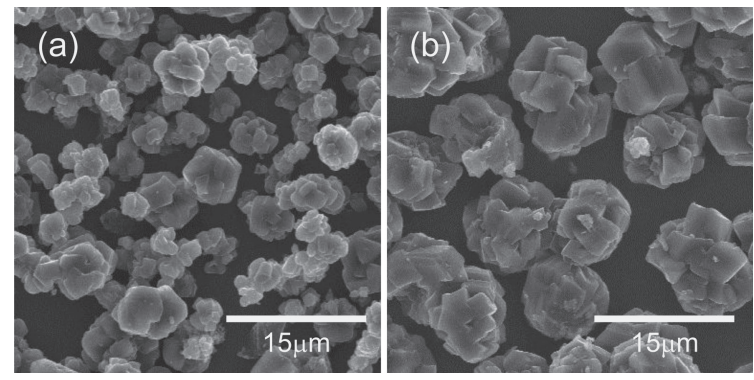

Fig. 8. SEM images of products obtained by heat treatment of (a) P3 and (b) $\mathrm{P} 6$ at $1250^{\circ} \mathrm{C}$ for $5 \mathrm{~h}$ in an $\mathrm{Ar}$ flow.
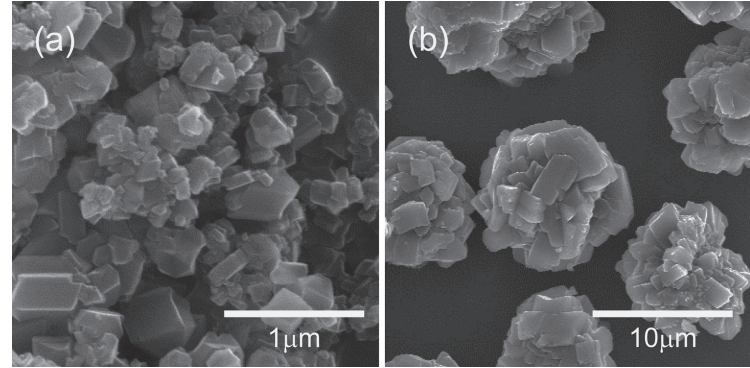

Fig. 9. SEM images of products obtained by heat treatment of (a) P3 and (b) $\mathrm{P} 6$ at $1150^{\circ} \mathrm{C}$ for $20 \mathrm{~h}$ in an Ar flow.

particles and the carbon matrix.

The SEM images of the products obtained by the heat treatment of $\mathrm{P} 3$ and $\mathrm{P} 6$ at $1250^{\circ} \mathrm{C}$ for $5 \mathrm{~h}$ in an Ar flow are shown in Fig. 8. The particles prepared from P6 $\left(D_{50}=10.0 \mu \mathrm{m}\right)$ were larger than those prepared from P3 $\left(D_{50}=4.8 \mu \mathrm{m}\right)$. Note that grain growth was observed in particles of both products. In the formation of $\mathrm{B}_{4} \mathrm{C}$ by the carbothermal reduction, the liquidphase reduction of $\mathrm{B}_{2} \mathrm{O}_{3}$ dominates at lower temperatures. The precursor prepared from a condensed $\mathrm{H}_{3} \mathrm{BO}_{3}$-PVA product has a carbon matrix, thus the carbon component is structurally connected throughout the precursor. The connectivity of the carbon component in a precursor is conducive to the grain growth of $\mathrm{B}_{4} \mathrm{C}$ since $\mathrm{B}_{4} \mathrm{C}$ is formed by reaction of liquid $\mathrm{B}_{2} \mathrm{O}_{3}$ at the surface of the carbon component. Our previous report revealed that the structural morphology of the precursor affected the morphology of $\mathrm{B}_{4} \mathrm{C}$ particles. ${ }^{13)}$ Figure 9 shows the SEM images of the products obtained by the heat treatment of P3 and P6 at $1150^{\circ} \mathrm{C}$ for $20 \mathrm{~h}$, illustrating the significant difference between the products. Although grain growth was observed in the particles of the product prepared from P6 $\left(D_{50}=9.1 \mu \mathrm{m}\right)$, only microparticles were observed in the product prepared from P3 $\left(D_{50}=0.42 \mu \mathrm{m}\right)$. These results imply that a finely dispersed precursor promotes the grain growth of $\mathrm{B}_{4} \mathrm{C}$ particles. The number of nucleation sites increased with increasing dispersion of the boron and carbon sources, thus promoting the formation of $\mathrm{B}_{4} \mathrm{C}$ and the subsequent grain growth of $\mathrm{B}_{4} \mathrm{C}$ particles even at a low synthesis temperature.

\section{Conclusions}

In this study, we investigated the effect of the PVA content of a condensed $\mathrm{H}_{3} \mathrm{BO}_{3}$-PVA product on the formation of $\mathrm{B}_{4} \mathrm{C}$ at a low synthesis temperature and its morphology. A precursor was formed by the thermal decomposition of the condensed $\mathrm{H}_{3} \mathrm{BO}_{3}-$ PVA product in air. The dispersibility of $\mathrm{B}_{2} \mathrm{O}_{3}$ particles in the carbon matrix of the microstructure markedly improved with increasing PVA content of the condensed product because $\mathrm{H}_{3} \mathrm{BO}_{3}$ molecules were more finely dispersed into the network of PVA chains. Crystalline $\mathrm{B}_{4} \mathrm{C}$ powder with a little free carbon was synthesized from a precursor with a more finely and homogeneously dispersed structure by the heat treatment at $1200^{\circ} \mathrm{C}$ for $5 \mathrm{~h}$ in an Ar flow. Furthermore, the formation and subsequent grain growth of $\mathrm{B}_{4} \mathrm{C}$ particles were promoted even at a low synthesis temperature.

Acknowledgement This work was partly supported by a Grantin-Aid for Young Scientists (B) (24750198) from the Japan Society for the Promotion of Science (JSPS).

\section{References}

1) F. Thevenot, J. Eur. Ceram. Soc., 6, 205-225 (1990).

2) A. K. Suri, C. Subramanian, J. K. Sonber and T. S. R. Ch. Murthy, Int. Mater. Rev., 55, 4-40 (2010).

3) H. Wada, S. Ito, K. Kuroda and C. Kato, Chem. Lett., 14, 691692 (1985).

4) H. Wada, K. Kuroda and C. Kato, Yogyo-Kyokai-Shi, 94, 6165 (1986).

5) A. Sinha, T. Mahata and B. P. Sharma, J. Nucl. Mater, 301, 165-169 (2002).

6) A. Sudoh, H. Konno, H. Habazaki and H. Kiyono, Tanso, 226, $8-12(2007)$.

7) A. K. Khanra, Bull. Mater. Sci., 30, 93-96 (2007).

8) A. M. Hadian and J. A. Bigdeloo, J. Mater. Eng. Perform., 17, 44-49 (2008)

9) I. Yanase, R. Ogawara and H. Kobayashi, Mater. Lett., 63, 9193 (2009).

10) M. Kakiage, N. Tahara, I. Yanase and H. Kobayashi, Mater. Lett., 65, 1839-1841 (2011).

11) M. Kakiage, N. Tahara, S. Yanagidani, I. Yanase and H. Kobayashi, J. Ceram. Soc. Japan, 119, 422-425 (2011).

12) M. Kakiage, Y. Tominaga, I. Yanase and H. Kobayashi, Powder Technol., 221, 257-263 (2012).

13) M. Kakiage, N. Tahara, Y. Tominaga, S. Yanagidani, I. Yanase and H. Kobayashi, Key Eng. Mater., 534, 61-65 (2013). 